\title{
Cryptocurrency Technology and Financial Reporting
}

\author{
Ahmad Shauqi Zubir, Nur Aishah Awi, Azwadi Ali, Safiek Mokhlis, Farizah Sulong
}

\begin{abstract}
Cryptocurrency technology is considered as smart technology that would transform our way of doing business in the near future. Its unique features are said to be far superior than our existing business technology which mainly based on cash and credit, especially in time, security and cost. Nevertheless, its entrance into the business arena has also turns our existing systems of financial reporting and taxing upside down as both systems were moulded, formulated and evolved just to suit the systems of cash and credit. Therefore, the financial regulators and inland revenue boards should come out with a new system that can properly and fairly adapt to the technology of cryptocurrency, in order to secure the imbalances between financial application and its law and order.

Key words: cryptocurrency, financial awareness, online payments, financial products, financial services, financial regulations, Bitcoin.
\end{abstract}

\section{INTRODUCTION}

Cryptocurrency is a type of "currency" that uses blockchain system and cryptography technique in doing transaction. The blockchain system connects the participants through their nodes (computers) while the cryptography technique is used in order to secure the "currency" transaction, either from the side of the remitter or the remittee. The system and technique are vital as the transaction is done peer-to-peer and without any intermediary. Hence, this is where the term cryptocurrency comes from. The US Financial Crimes Enforcement Network and European Legislation use more general definitions for cryptocurrency, which are "convertible digital currencies" and "digital equivalent of cash", respectively (Papadopoulos, 2015).

Most of the cryptocurrencies can be obtained through mining. This mining process is largely a process of maintaining the network of a cryptocurrency by verifying and recording the transactions of the cryptocurrency. Because of this maintaining process requires computers, certain hardwares, softwares and consume a lot of electricity, as well as other necessities, the miner is rewarded with new similar cryptocurrency.

Revised Manuscript Received on May 15, 2020.

* Correspondence Author

Dr. Ahmad Shauqi Haji Mohamad Zubir*, Lecturer, School of Business and Maritime Management, University, Malaysia. E-mail: shauqi@umt.edu.my

Dr. Nur Aishah Awi, Lecturer, School of Maritime Business and Management, University Malaysia. E-mail: nuraishah@umt.edu.my

Dr. Azwadi Ali, Associate Professor, School of Maritime Business and Management, University Malaysia. E-mail: azwadi@umt.edu.my

Dr. Safiek Mokhlis, MCIM, MIMM, Associate Professor, University Putra, Malaysia. E-mail: safiek@umt.edu.my

Dr. Farizah Sulong, ACCA, CA (M) Lecturer, School of Maritime Business and Management, University Malaysia. E-mail: farizah.sulong@umt.edu.my

(c) The Authors. Published by Blue Eyes Intelligence Engineering and Sciences Publication (BEIESP). This is an open access article under the CC BY-NC-ND license (http://creativecommons.org/licenses/by-nc-nd/4.0/)
The mining process led to the robustness of cryptocurrency system from double spending and counterfeiting activities. Other than that, cryptocurrency can be bought and sold through exchanges, which primarily act as intermediaries for the exchange of fiat currencies with cryptocurrencies vice versa, or for the exchange of one type cryptocurrency with another type of cryptocurrency.

As of today, there are more than 2500 cryptocurrencies worldwide, more than 2000 cryptocurrency companies and more than 70 global cryprocurrency exchanges. At the end of 2018, the market capitalisation regarding the cryptocurrency businesses is more than USD250 billion (Othman et al., 2019).

Transaction of cryptocurrency requires public key and private key. Public key or address is used for transactions hence can be accessed or known to other people than the owner of the cryptocurrency, while private key is used to authorise the transaction, hence can only be known to the owner himself. The transaction consists of the addresses of the parties involved, authorisation by the owner of the account and verification by the cryptocurrency network participants. All of these are done using cryptography. Hence, the sender and the receiver in the transaction process cannot be identified based on the information on that transaction alone. The transaction, however, is recorded in the cryptocurrency system or also known as a blockchain system, which includes the time, the public keys and the amount involved. These are viewable to the network's participant (Nian and Chuen, 2015). 


\section{Cryptocurrency Technology and Financial Reporting}

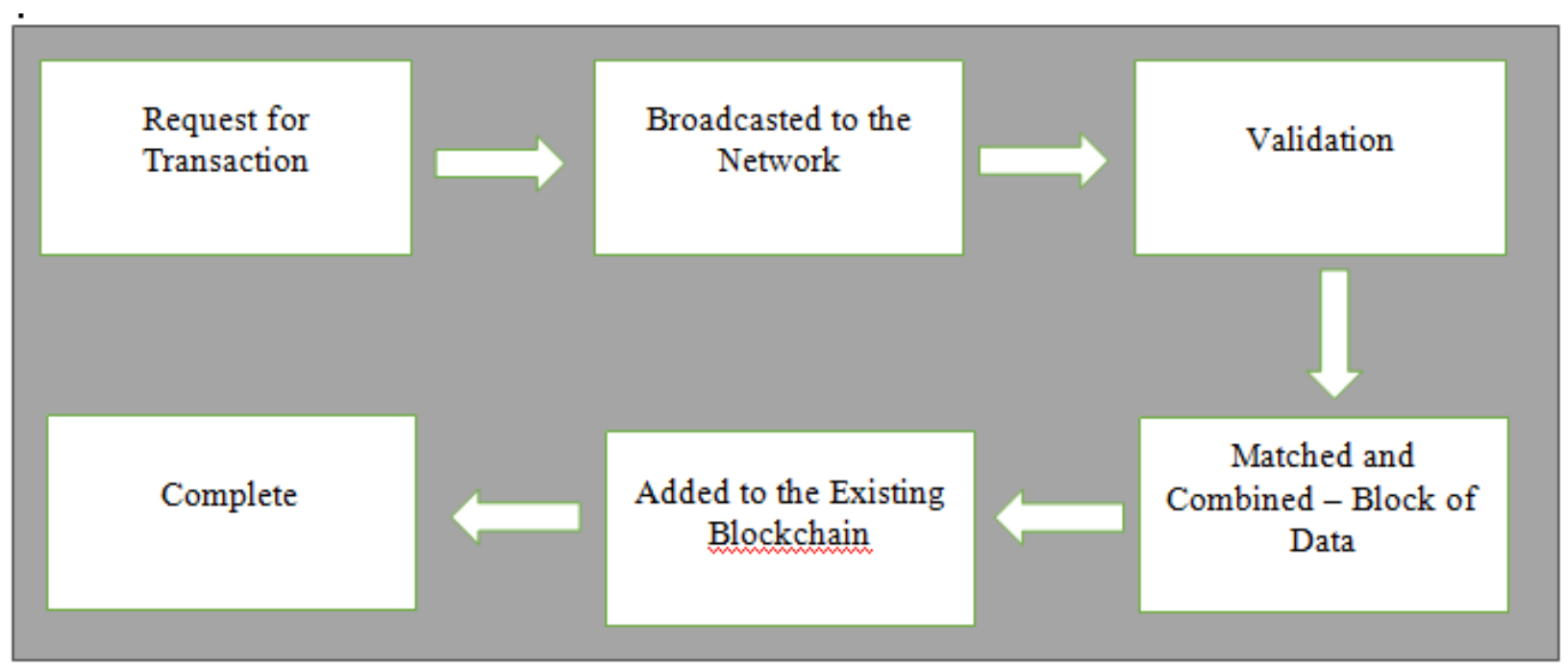

Figure 1: The Transaction Process of Cryptocurrency

Because of that, the transaction is called as unregulated. To regulate things, precise information is of course needed. Also, intermediary to that transaction is also needed to guarantee the validity of the said information. These two things are purposely left from the cryptocurrency system in order to achieve what they call as financial freedom and elimination of third-party profit taking. Yes, with cryptocurrency you can use your money/currency to buy anything, anywhere and at any time as it is based on peer-topeer, your personal information would not be revealed and no one will charge you the fee for the remittance. On the other hand, because of the so-called freedom, the loss of private key is irretrievable and if it is stolen, further transactions after the loss cannot be stopped as there neither intermediary nor information of the true owner of the cryptocurrency. Also, because of that, cryptocurrency is often associated with illegal goods, services and other criminal activities such as money laundering and terrorist funding (Saito, 2015).

\section{PROBLEM STATEMENT}

The use of cryptocurrency has alarms many governments worldwide. Laws and regulations were and are still being formulated regarding how to treat and tax the cryptocurrency. Not only cryptocurrency will revolutionised the daily life of the individuals, but also the financial system as a whole. Enterprises, even public listed companies and government would be effected if the cryptocurrency is being used in a large scale to replace the fiat money. Just imagine how should tax collection works efficiently if cryptocurrency doesn't offer precise information of the involved parties in a transaction. And tax is only one part in the financial system which also includes the existing foreign exchange, capital markets, central banks, debt markets and others which have their own set of rules, and those set of rules are based on fiat money and intermediaries. Some people opine that cryptocurrency may not replace fiat money, at present or in the near future but some believe that it has slowly but surely replacing the latter in certain parts of our daily life. For example, the activity of Initial Coin
Offering (ICO), the acceptance of cryptocurrency by the online marketplaces, the rapidly increased of the number of cryptocurrency exchanges, and the increased number of cryptocurrrencies and their market capitalisation. All of these happened because cryptocurrency has been accepted and used, although not entirely, to replace fiat money. Further, the blockchain technology that comes with the cryptocurrency has also been accepted very well in many areas and led to the application of smart contract (Joo et al., 2019). Another example is when Bitcoin were used in financing formal company's acquisition in 2013, which is when Zeroblock were acquired by Blockchain, although the amount of bitcoin used is not disclosed. Also, SatoshiDice company were acquired by an undisclosed company by using bitcoin that worth $\$ 11.5$ million at that time (Kharpal, 2014). Basically, money is needed to buy things. A universally accepted description of money is a 'thing' that is regulated by law and recognised by the buyer and seller as an exchange medium that can be divided into smaller units and its nominal value does not change from time to time. These characteristics can be found in all government-issued fiat money but not entirely in cryptocurrency. The only similar characteristic between the fiat money and the cryptocurrency is both are accepted in online transaction, but limited to certain marketplaces and certain buyers and sellers in the case of cryptocurrency. For now, majority of the government worldwide do not recognise cryptocurrency as money, hence the use of the cryptocurrency is deemed as unregulated by law. Further, although cryptocurrency can be divided into smaller units, the process of determining the precise value of the smaller units is burdensome and difficult. Take Bitcoin for example. Its value is highly volatile and far higher compared to US Dollar and other fiat currencies. 
At the time of this writing, 1 Bitcoin is equal to $10,162.50$ US Dollar. A year before, 1 Bitcoin is valued less than half of that Dollar amount, in which 1 Bitcoin equals 3,648.84 US Dollar. Two years before, 1 Bitcoin equals 8,547.49 US Dollar and two days before, 1 Bitcoin equals not more than 10,000 US Dollar. Likewise, as most daily goods or services are priced in fiat money currencies and not many of them are priced equal to or more than 10,000 US Dollar per unit or package, the unit or package would be quoted in at least 4 decimal places if converted to Bitcoin (Yermack, 2015). And these volatility and high value characteristics are the nature of many cryptocurrencies and are extremely difficult to be eliminated. Although one might say that the advancement of technology nowadays may enables the seller to provide updated prices in cryptocurrency denominations from time to time as prices do change, the changes would occur far more rapid and would cause distress not only to the buyer but also to the seller, the manufacturer and others as technology sometimes fails to deliver what it promised and the technology also differs across time and places. As a conclusion, cryptocurrency does not meet the requirements to be regarded as money.

\section{CRYPTOCURRENCY IN ACCOUNTING AND FINANCE}

Cryptocurrency is needed in order to fully utilised the blockchain system. This is in line with the purpose of deploying the blockchain system, that is, to eradicate the intermediary, costs and processing time, and at the same time the transaction is immutable. Because of that, the record of the transaction will be permanent and can't be altered. Thus, financial rules and regulations should be amended in order to include cryptocurrency in the financial system, for the sake of adapting the blockchain technology, not just in the financial arena but also in many other fields (Potekhina and Riumkin, 2017).

By using blockchain system, the transaction's record will be available in real-time to public, if it is set to such setting. This type of transparency may or may not be preferred by companies and others, but companies will have the choice to whether set the record to be publicly available, or only certain parties such as stakeholders, managers and officials will have the privilege to access the record. Nevertheless, above all, public companies do not have a similar privacy right as individuals, as they are responsible to the public, by providing them information, which are authentically, reliably and timely accurate (Tapscott and Tapscott, 2016). Hence, the use of blockchain system in accounting does meet the objective of financial reporting in that sense and would improve the confidence in financial market which has been tampered with frauds and scandals, or at least alleviate the financial market information asymmetry (Yu et al., 2018; Yermack, 2017; The Economist, 2015). ICAEW IT Faculty (2018) states that blockchain is a new accounting breakthrough that simplify the transaction, or transfer of assets and proprietorship, while at the same time providing accurate information by producing a real time ledger and upholding the ledger for the interest of the participants. As a result, blockchain system can at least, take over the task of obtaining clarity over proprietorship, obligations and indemnities, which are parts of critical accounting procedures. Most importantly, the cost-diminishing effect that it would bring to the process of preparing financial reporting is interesting and tempting to most accounting service companies. The blockchain system is also said to substitute the job of an accountant as it records and verifies all transactions without the need of intermediation by any accountant or auditor. In other words, blockchain provides an automated accounting system which could save time and money compared to the current human accounting system. This potential risk or benefit in accounting field, has been documented by the Australian Department Industry (2014). They further elaborate that the only barrier to the automated system to replace the accountant is the superiority of human accountant compared to automated system, which is: "the ability to solve problems intuitively, improvise spontaneously and act creatively". Correspondingly, the human accountants could concentrate their resources on verifying, planning and appraising, which are also parts of financial responsibilities (Deloitte, 2016). On the contrary, the blockchain system can be used to manipulate the financial report by performing certain cryptocurrency transactions. This is done to achieve certain figure in the record. If this is done, the legitimacy of such transaction needs to be verified by the auditor. Perhaps the task of human in accounting would be reallocated to certifying and verifying business documents, or perhaps smart contracts in the era of blockchain, as her original duty has been taken by the blockchain (Yu et al., 2018). Blockchain is also unregulated, distributed worldwide and based on nodes that are only known by their pseudonyms. As a result, no proof of identity involved in the transaction and it is difficult for any revenue agency to track the transaction details, for the purpose of correctly taxing either the sender or the recipient. At least, that is the case with companies like Airbnb and Uber (Potekhina and Riumkin, 2017). Further, if there are nodes conspiring in order to achieve certain objective, or somehow there is an accidental error that led to the insertion of incorrect data to the block, corrective measures would be hard to be implemented, at least would not be done in a short period.

\section{ISSUES AND IMPACTS IN ACCOUNTING AND FINANCE}

The holdings of cryptocurrencies can be in huge amount and the value of cryptocurrencies are usually volatile. Thus, financial practitioners would likely have to struggle to learn about them. Most accountants would agree that it would be fair value that would best account for a cryptocurrency as it is the value that can be invested or traded for the desired goods or services. However, the current accounting regulations haven't considered the treatment of cryptocurrency yet. Published By:
Blue Eyes Intelligence Engineering
$\&$ Sciences Publication

(C) Copyright: All rights reserved.






\section{Cryptocurrency Technology and Financial Reporting}

Lugo (2013) states that the formal accounting treatment for cryptocurrency has not being announced yet by the Financial Accounting Standards Board (FASB), the organisation who sets accounting standards which are adapted by public companies, but so far, the treatment should conform the other comprehensive accounting basis, and this is still the case at the time of this writing. Consequently, one of the issues regarding cryptocurrency is the taxation procedure for its transaction. To overcome this, Swan (2015) suggests that the taxation system should be changed to taxing on consumption, that is by taxing people when they spend, especially on observable items, instead of taxing on income. However, the procedure for this system in the cryptocurrency environment is still unclear especially on services and taxing on consumption also raises other issues as it would has asymmetric impact on public, with the largest impact would be on retired person group, lowincome and middle-income households (Garner, 2005). Because of the cryptocurrency's popularity, businesses are becoming tolerant in doing cryptocurrency-based transaction, either with other companies or with their consumers. Nevertheless, another issue arose; the accounting treatment on cryptocurrency. Cryptocurrency doesn't fit into financial asset classification as it can't be considered as cash and also doesn't promised any cash to its holder. Hence, cryptocurrency should be treated as inventory and be measured at cost (Gary Berchowitz, ACCA, 2018). Although cryptocurrency should be treated as asset, it can't be treated as money, as money is regulated as legal tender under the law. Hence, cryptocurrency can't also be treated as cash. Further, cryptocurrency also does not fit the classification of electronic payment according to the Central Bank of Finland as cryptocurrency transaction is done based on pseudonymity. That is, the person who issued and responsible for the payment is not formally known (Pohjanpalo, 2014). Not only that, cryptocurrency is also not recognised as a real currency in China, Norway, Korea and Germany (Yang, 2013; Russell, 2013; Werdigier, 2013). Likewise, the United States Financial Crimes Enforcement Network (FinCEN) suggest that cryptocurrency only acts as an electronic trading system and can be considered as partly currency. It fails to fulfil the requirement of either real currency or legal tender (Fisher and Kaplinsky, 2013; Procter, 2014). One of the main issues in fulfilling the definition of cash is liquidity. Cryptocurrency is not as liquid as cash or can be easily converted into cash. Many financial institutions, dealers, merchants, traders or even individuals do not accept cryptocurrency, at least yet. In other words, the usage is still limited. The other thing is cryptocurrency does not fluctuates accordingly to the cash in value. One could easily argue that to be considered as cash, cryptocurrency's value has to be similar to cash, in any denomination. The only category that fits cryptocurrency is investment (Raiborn et al., 2015). This categorisation has simplified the journal entry when cryptocurrency transaction occur; investment account is debited with cryptocurrency purchase and the account is credited with either cash, or revenue, or payable or any item used in the cryptocurrency transaction.
However, there is another accounting's complication regarding cryptocurrency; mining. That is, how do we treat cryptocurrency mining for financial reporting? This question arose as the mining process can vary according to events. Consider a first event where an employee of a company obtained certain amount of cryptocurrency for the company through mining. The proposed solution for this event is to categorise the cryptocurrency as inventory, or as software which is developed by the company, or even as an asset and an unrealised gain simultaneously, when the cryptocurrency is incurred. In the second event, assume that it is a partner in a company one who obtained the cryprocurrency for the company. The proposed solution is to categorise the cryptocurrency as an investment for ownership from that partner and is credited to the capital account. The same goes for a sole proprietorship company. In the third event, assume that it is a stock holder who did the mining. The proposed solution is to award or issue certain amount of stock in exchange of the cryptocurrency, or to pay in cash for the cryptocurrency (Raiborn et al., 2015). A company would likely use cryptocurrency for reporting purpose by holding the cryptocurrency during the financial reporting period. If this happens, the cryptocurrency, which is treated as an investment, would be presented at fair value, producing unrealised profit or deficit on the balance sheet. However, as formal accounting treatment for this case is still undeclared yet, the question whether the profit or deficit are considered as periodic net income or comprehensive income remains. The problem with determining fair value of cryptocurrency is it usually resulted in more than one value as there is more than one exchange that can be used to assess it. Moreover, the point of time used in the assessment process is likely to be inaccurate as the volatility of the cryptocurrency is high. Not only that, there is also a probability that the addressee of the cryptocurrency would pump up the exchange with cryptocurrency in order to raise its value.

\section{IMPLEMENTATION IN MALAYSIA}

Survey interview with 10 chartered accountants in Malaysia were conducted in order to gain the insight knowledge of cryptocurrency in financial reporting from the perspective of practitioners. The purpose of the survey is to measure the awareness, experience, treatment and to analyse if there is any suggestion for the improvement in accounting treatment of cryptocurrency. The accountants were chosen randomly from Peninsular Malaysia and are all have more than 5 years working experience in accounting and auditing, and had more than 500 clients between them. They are all aware of the cryptocurrency's existence and how to use the cryptocurrency but all of them have never encountered any cryptocurrency while working with their clients, whether while doing accounting services, auditing, verbal consultation and taxation works. The opinion regarding accounting and tax treatment on cryptocurrency in Malaysia however, varies.
Published By:
Blue Eyes Intelligence Engineering \& Sciences Publication (C) Copyright: All rights reserved.

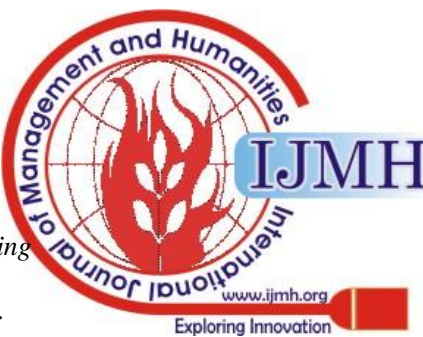


On top of that, majority of them (8 out of 10) suggest that Malaysia should not recognise cryptocurrency as legal tender and it should be barred from being used in similar manner as fiat currency. Further, all of them won't recommend the use of cryptocurrency to their clients. The main reason for the bar action and the inadvisable is the value of cryptocurrency that is difficult to be determined in reality, in which this type of treatment has never been encountered in the accounting field before. The other reason is there is still no Malaysian accounting standard or procedure to be followed yet in treating the cryptocurrency.

\section{CONCLUSION}

The main purpose of financial reporting is to present information regarding financial position of a company so that stakeholders, creditors, investors and others would understand and take appropriate decision regarding that company, although they might have a basic level of financial understanding. Nevertheless, the complexity of accounting treatment for cryptocurrency seems to make financial reporting more difficult to the users and problematic to the providers. Hence, alarm bell should be rang when a company deals with cryptocurrency, which might lead to misreporting, and failing to provide full financial disclosure has led to the fall of many previous companies such as Enron. Further, guidance on financial reporting relative to cryptocurrency should be resoluted, declared and regulated, in order to uphold the main purpose of the financial reporting itself. Albeit of its complexity, cryptocurrency should not be abandoned by the accounting world as its transaction, whether made by individuals or companies, has increased. Thus, implications to the accounting world, which are carried by the cryptocurrency, need to be properly addressed before another accounting saga of fraud, violations, misappropriation and misdeed emerged.

\section{REFERENCES}

1. Berchowitz, G. (2018) Fair value or at cost? Bitcoin throws accounting a curveball. ACCA [online], Tuesday $1^{\text {st }}$ May. Available from: https://www.accaglobal.com/us/en/member/discover/cpdarticles/financial-management/bitcoinacc-cpd.html [Accessed 25 December 2018].

2. Deloitte (2016) Blockchain Technology: A game-changer in accounting? [online]. Available from: https://www2.deloitte.com/content/dam/Deloitte/de/Documents/Innova tion/Blockchain_A\%20game-changer\%20in\%20accounting.pdf [Accessed 30 January 2019].

3. Fisher, K. \& Kaplinsky , A. (2013). FinCEN issues virtual currency guidance. JD Supra [online], Monday $25^{\text {th }}$ March. Available from: http://www.jdsupra.com/legalnews/fincen-issuesvirtual-currencyguidance-17773 [Accessed 22 January 2019].

4. Garner, C. A. (2005) Consumption taxes : macroeconomic effects and policy issues. Economic Review, (Q II): 5 - 29.

5. Goodwin Procter (2014) FinCEN issues guidance on virtual currency [online]. Available from: http://www.goodwinprocter.com/DoddFrank/Publications/Newsletter\%20Articles/Consumer\%20Financial\%2 0Articles/2013_04/07_06.aspx [Accessed 30 January 2019].

6. Hasan Abdullah Othman, A., Musa Alhabshi, S., Kassim, S., \& Sharofiddin, A. (2019) The impact of cryptocurrencies market development on banks' deposits variability in the GCC region. Journal of Financial Economic Policy, 11(4): 1 - 24

7. ICAEW IT Faculty (2018) Blockchain and the future of accountancy [online]. Available from: https://www.icaew.com/technical/technology/blockchain/blockchain- articles/blockchain-and-the-accounting-perspective [Accessed 30 January 2019].

8. Joo, M. H., Nishikawa, Y., \& Dandapani, K. (2019). ICOs, the next generation of IPOs. Managerial Finance.

9. Kharpal , A. (2014) Bitcoin: The future of M\&A deals? CNBC [online], Wednesday $12^{\text {th }}$ March. Available from: https://www.cnbc.com/2014/03/12/bitcoin-the-future-of-ma-deals.html [Accessed 12 January 2019].

10. Lugo, D. (2013) No GAAP for bitcoins FASB discussions indicated. Bloomberg [online], Monday $16^{\text {th }}$ December. Available from: http://www.bna.com/no-gaap-bit-b17179880752/

11. Nian, L. P., \& Chuen, D. L. K. (2015). Introduction to Bitcoin. In Handbook of Digital Currency (pp. 5-30). Academic Press.

12. Papadopoulos, G. (2015) Blockchain and Digital Payments: An Institutionalist Analysis of Cryptocurrencies. In Handbook of Digital Currency (pp. 153-172). Academic Press.

13. Parkins, D. (2015) Blockchain: The great chain of being sure about things. The Economist [online], Saturday $31^{\text {st }}$ October. Available from: https://www.economist.com/briefing/2015/10/31/the-great-chain-ofbeing-sure-about-things [Accessed 12 January 2019].

14. Pohjanpalo, K. (2014) Bitcoin deemed a commodity not a currency in Finland [online], Monday $20^{\text {th }}$ January. Available from http://www.sfgate.com/technology/article/Bitcoin-deemed-acommoditynot-a-currency-in-5160291.php [Accessed 20 January 2019].

15. Potekhina, A. and Riumkin, I. (2017) Blockchain - a new accounting paradigm: Implications for credit risk management. Master Thesis, Umeå School of Business and Economics, Umea University, Umea (Sweden).

16. Raiborn, C. \& and Sivitanides, M. (2015) Accounting Issues Related to Bitcoins, The Journal of Corporate Accounting \& Finance, (January/February 2015): 25 - 34

17. Russell, J. (2013). Norway rejects bitcoin as a legitimate currency, will treat savings as taxable assets. TNW [online], Monday $16^{\text {th }}$ December. Available from: http://thenextweb.com/insider/2013/12/16/norwayrejects-bitcoin-legitimatecurrency-

18. Saito, T. (2015). A Microeconomic Analysis of Bitcoin and Illegal Activities. In Handbook of Digital Currency (pp. 231-248). Academic Press.

19. Swan, M. (2015) Blockchain: Blueprint for a New Economy. $1^{\text {st }}$ ed. Sebastopol: O'Reilly Media.

20. Tapscott, D. and Tapscott, A. (2016) Blockchain Revolution: How the Technology Behind Bitcoin Is Changing Money, Business, and the World. $1^{\text {st }}$ ed. New York: Portfolio/Penguin.

21. Werdigier, J. (2013) European Union warns on bitcoin. NYTimes [online], Friday $13^{\text {th }}$ December. Available from: http://dealbook.nytimes.com/2013/12/13/european-union-warns-onbitcoin/ [Accessed 21 January 2019]. will-treat-savings-taxableassets/\#!sORYf [Accessed 21 January 2019].

22. Yang, S. (2013) China bans financial companies from bitcoin transactions. Bloomberg [online], Thursday $5^{\text {th }}$ December. Available from http://www.bloomberg.com/news/2013-12-05/china-s-pbocbans-financialcompanies-from-bitcoin-transactions.html [Accessed 20 January 2019].

23. Yermack, D. (2015). Is Bitcoin a Real Currency? An Economic Appraisal. In Handbook of Digital Currency (pp. 31-43). Academic Press

24. Yermack, D. (2017) Corporate governance and blockchains. Review of Finance, 21(1): 7 - 31.

25. Yu, T., Lin, Z. and Tang, Q. (2018) Blockchain: The Introduction and Its Application in Financial Accounting. The Journal of Corporate Accounting \& Finance (October 2018), 37 - 47.

\section{AUTHORS PROFILE}

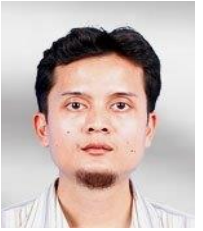

Dr. Ahmad Shauqi Haji Mohamad Zubir PhD (Birmingham), MSc Quantitative Sc. (Fin Eng) (UiTM), BSc (Hons) Act. Sc. (UKM) Lecturer

Email: shauqi@umt.edu.my | Phone: +609 6683794

Dr. Ahmad Shauqi Bin Haji Mohamad Zubir is a finance lecturer at the School of Business and Maritime Management, Universiti Malaysia Terengganu (UMT), with more than 10 years teaching experience in the field. He holds a $\mathrm{PhD}$ in finance from the University of Birmingham.

Published By:
Blue Eyes Intelligence Engineering \& Sciences Publication

(C) Copyright: All rights reserved.

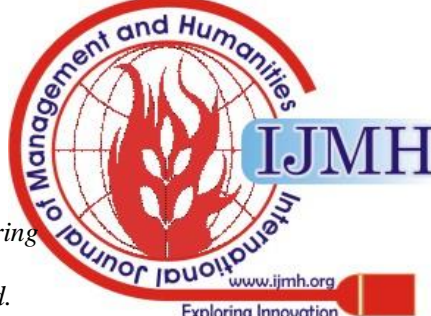




\section{Cryptocurrency Technology and Financial Reporting}

He was an affiliate of Registered Financial Planner, Malaysian Financial Planning Council and also a finance officer before taking the role as a lecturer at UMT. His main research interest includes mathematical and econometrical modelling in finance, profitability analysis of financial assets and transactions, practicality of Islamic economics and finance, and investment evaluation and analysis.

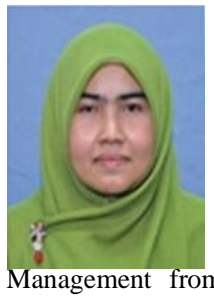

Dr. Nur Aishah Awi

PhD (Coventry), MSc, BSc (Hons), Diploma (UiTM) Lecturer

Email: nuraishah@umt.edu.my | Phone: +6096684151 Dr. Nur Aishah is a lecturer of Management (Marketing) programme at the School of Maritime Business and Management, Universiti Malaysia Terengganu. She holds a PhD in Strategy and Applied Manage from Coventry University, United Kingdom. She taught Operation Management and Management Principle. Her current research interests includes operation management, lean management and quality management.

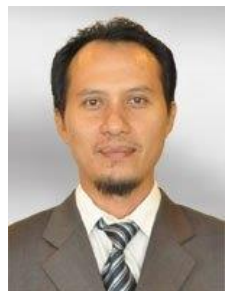

Dr. Azwadi Ali

PhD (Victoria), MAcc (UiTM), BA (Hons) Acc \& Fin (Lancaster) Associate Professor | Chairman of the Bachelor of Accounting Programme Email: azwadi@umt.edu.my | Phone: +609 6683449Dr.

Azwadi Ali is an associate professor at the School of Maritime Business and Management, Universiti Malaysia Terengganu. He holds a Bachelor of Accounting and Finance from Lancaster University (UK), a master's degree in Accountancy from UiTM, and a Ph.D. from Victoria University (Australia). He has taught mainly Accounting Information Systems and finance-related subjects at the school for more than ten years. His research interests include personal finance and accounting information systems (user perspective). He has published his research works in a number of journals and has been appointed as graduate thesis examiner, both inside and outside UMT.

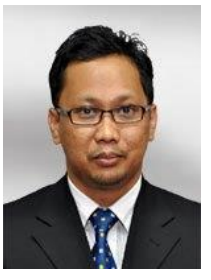

Dr. Safiek Mokhlis, MCIM, MIMM

PhD (Stirling), MSc (UPM), BBA (UPM)

Associate Professor

Email: safiek@umt.edu.my | Phone: +6096684188 / 4823

Dr. Safiek Mokhlis obtained his BBA and MSc degrees from Universiti Putra Malaysia, and a $\mathrm{PhD}$ from the University of Stirling, Scotland. He is a member of the Chartered Institute of Marketing (UK) and the Institute of Marketing Malaysia. He started his academic career in 2001 as Tutor, appointed as Lecturer in 2006, as Senior Lecturer in 2009, and as Associate Professor in 2013. He has taught a wide range of marketing courses at undergraduate level, including Retailing Management, Consumer Behavior, Marketing Research, Services Marketing, Product Management, and Channel Management. His research interests lie in the field of marketing, particularly consumer behavior. Specific interests include cultural influences on consumer behavior, consumer socialization, shopping orientation, retail patronage and service quality. He has published over 50 journal articles in these areas.

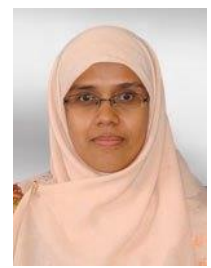

Dr. Farizah Sulong, ACCA, CA (M) $\mathrm{PhD}$ (IIUM), M. Com \& Admin (Acc) (Wellington), B.Com \& Mgt (Lincoln) Lecturer

Email: farizah.sulong@umt.edu.my

Dr. Farizah Sulong is a Tutor under the School of Maritime Business and Management, Universiti Malaysia Terengganu. She holds a $\mathrm{PhD}$ from International Islamic University Malaysia, Bachelor of Commerce and Management Degree from Lincoln University, New Zealand and Masters of Commerce and Administration (Accountancy) Degree from Victoria University of Wellington, New Zealand. She is also a Chartered Accountant registered with the Malaysian Institute of Accountants (MIA) and Association of Chartered Certified Accountants (ACCA). Her research interests include environmental management accounting, sustainability accounting and management accounting. 